\title{
The Integration of Classic Cars as an Alternative Investment in Wealth Management Environments and the Possible Influence of Behavioral Finance
}

\author{
Sebastian Hoffmann \\ Ph.D. Student of USC - University of the Sunshine Coast, Australia, \\ in association with SMBS - University of Salzburg Business School, Austria
}

\begin{abstract}
Investing in classic cars can be a supplement to traditional investments for private clients in wealth management. However, the special features of this exotic asset class have to be taken into account. In the case of an investment, risk factors such as ongoing costs, market transparency and liquidity have to be considered. In contrast, opportunities arise from potential portfolio optimization as well as of the realization of an "emotional return". General return forecasts can only be made to a limited extent. Rather, it requires an individual yield calculation, taking the circumstances and intentions of the investor into account. The Classic Car Banking Concept, which is presented in this paper, demonstrates the ability to integrate the investment in classic cars into an existing wealth management structure. Thereby, the further diversification of an investor's portfolio by adding classic cars offers an interesting earning potential in the current situation of historically low interest rates in many parts of the world. Moreover, Classic Car Banking as a segment of wealth management in general has the potential to use the conceivable emotional involvement of investors in order to intensify the relationship between clients and consultants. Nevertheless, selected concepts of behavioral finance are able to explain the downside of potentially emotional investments. Concepts such as Anchoring, the Endowment Effect, Mental Accounting and Overconfidence are related to insufficient decision making which, in the case of investments, leads to inadequate monetary returns.
\end{abstract}

Keywords: Wealth Management, Classic Cars, Behavioral Economics, Behavioral Finance

\section{Introduction}

The current market environment for capital investments is shaped by the persistently low interest rate environment. Against this background, it is understandable that investors of all kind, for example private investors and professionals from capital investment services, are looking for new investment opportunities with above-average returns (Sauren, 2015). Investing in classic cars thereby is an option in the area of alternative or exotic asset classes. In the meantime, this investment is no longer treated only in automotive-specific journals, but is increasingly also the subject of a scientific debate. However, the investment in the so-called "garage gold" has been considered rather isolated until now. This paper aims to provide possibilities, on how to integrate the investment in classic cars into an existing service portfolio of wealth management as a so called Classic Car Banking.

An analysis of the asset class classic cars will be provided in the following. This includes an insight on the technical terms, an overview of the market participants, the intentions of classic car acquisition as well as factors of measurable value development. On this basis, different possible types of investments in the asset class will be presented, with due regard to specific opportunities and risks. Subsequently conclusions can be drawn on how the investment in classic cars can be operationalized in an existing wealth management structure. For this purpose, a model is presented, which reflects the customers' needs around the investment in classic cars. The model implies, which need can be covered by the core competencies of wealth management and where additional consulting is needed. 


\section{Classic Cars as an Asset Class}

The analysis of the classic car asset class is in the following limited to passenger cars. Historic motorcycles as well as historical agricultural machines are, although fundamentally also conceivable as investment objects, not the subject of the further consideration in this paper.

The recognition of a vehicle as a classic car depends on the definition. In Germany for example, the recognition is regulated by law ( $\S 23$ Straßenverkehrs-Zulassungs-Ordnung - StVZO). According to the relevant regulation, the vehicle must be assessed by an officially recognized expert or examiner. There are four basic requirements which are regularly needed for a recognition as a classic car. The vehicle must be at least 30 years of age, the originality of all assemblies has been retained, the condition can be considered worth preserving and modifications to the vehicle have been made only to a limited extent (TÜV Süd Autoservice $\mathrm{GmbH}, 2012$ ). In particular, the originality of a vehicle as well as the condition worthy of preservation are the keys to a future increase in value. The fulfillment of the criteria mentioned before, leads to road traffic law recognition as a classic car in Germany. The latter allows approval as a historic vehicle $\mathrm{H}$-approval with specific license plate). There are some advantages and possibilities associated with this, such as a flat-rate motor vehicle tax or the unrestricted travel in environmental zones (GTÜ Gesellschaft für technische Überwachung mbH, 2016). In addition, this classification allows insurance in special vintage tariffs with extended insurance benefits (Anastassiou, 2013).

The possible intentions for investing in a vintage car are almost always individual, but the majority of motives can be aggregated to two main intentions. On the one hand, these are emotional intentions and, on the other hand, rational expectations of a monetary return. In practice, a combination of both intentions with corresponding emphasis will often be encountered.

Literature suggests, that the investment in classic cars can be referred to as a so-called passion investment. In addition to classic cars, this asset class includes works of art, jewelry or wine (Kräussl, 2015). This list already shows the character of an emotional investment. These are haptic objects, to which a clear individual preference of the owner can be assumed regularly. For example, the owner of a classic car can experience emotionally positive moments by using the vehicle. This incorporates the realization of a so-called emotional return, for example by continuous caretaking of the automobile or by opposing appreciation when participating in classic car events (Merten, 2015).

The second purpose of classic car acquisition is the intention of yielding. As early as $2012,23.0 \%$ of classic car owners in Germany viewed their vehicle primarily as an investment (bbg Betriebsberatungs $\mathrm{GmbH}, 2012$ ). Particularly in the years following the financial crisis, investment flows have increasingly shifted to tangible assets and thus to the classic car market as well. Private investors apparently perceive the investment in classic cars as a way out of low interest rates and inflationary fear (Euler, 2014). Moreover, a growing popularity of the investment class with yield investors is encouraged by high-profile auctions with record sums (Jahnstone, 2014).

In terms of the performance of classic cars, there are special features to be considered that distinguish this asset class from almost all others. In the following, the three significant factors (extreme) rarity, condition and origin of the vehicle will be further examined (Barzilay, 2009).

Initially, classic cars are a type of commodity which are not reproduced in its specification under usual circumstances. Nevertheless, there are differences in the impact of this fact. As in all markets, supply and demand determine the price. Vehicles that have been produced in larger quantities and have a correspondingly large supply will tend to participate less in value increases. When choosing an investment object, one should therefore pay attention to the rarity of a vehicle. Extremely rare vehicles are considered those, which have been produced only in small series or even as individual pieces. Although enormous increases in value are possible here, the highly limited supply of spare parts should also be considered (Barzilay, 2009).

The second factor of performance considers the condition of the vehicle. It should be noted that, for example by restoring, significant increases in value can be observed. This is a decisive unique feature of the asset class classic cars. By the owners' own intervention, a significant increase in value is possible. This is almost impossible with traditional investments, such as stocks or bonds, and is also limited in other exotic investments such as art and wine (Thaddeus, 2012).

A third factor that can significantly add value to a vehicle is its history. In addition to the performance of a single vehicle, this can sometimes also impact complete series or brands. For example, a Porsche $911 \mathrm{~S}$ from 1971 was sold at an auction 
in 2011 at $\$ 1,375,000$, which was about six to eight times the value of comparable vehicles. Obviously, the cause was a prominent previous owner: Steve McQueen (Rotz, 2012). Moreover, the performance of a brand in terms on value-adding can be influenced by the use of the vehicles in films as well as by celebrity use (Kräussl, 2015a). Furthermore, the so-called racing history occupies a special position with regard to the value-adding potential. For example, vehicles of the Ferrari brand that are used in motorsport events such as the Le Mans race are particularly expensive (Brückner, 2013).

Only a few years ago, mainly technically experienced people, who could do repairs themselves, owned vintage cars. However, the group of those who mainly enjoy the possession and the movement of the vehicle, but have no technical expertise, grows (Trockner, 2011). Besides the purely quantitative expansion of the market for classic cars, also a broadening of interests as far as the buyers are concerned can be observed. Based on the various investment opportunities, the classic car market will be examined in more detail below.

Basically, there are three ways to acquire a classic car. A survey among classic car owners in 2012 revealed that the majority of respondents purchased their car in a private sale. Thereby, upfront research on the internet also played a key role. In total, more than $25 \%$ of the vehicles were finally purchased on the Internet (bbg Betriebsberatungs $\mathrm{GmbH}, 2012$ ). Moreover, for higher-priced vehicles, the purchase at auctions was observable (Phillip, 2014).

Another possibility of classic car acquisition is the purchase from commercial classic car dealers. Here, a distinction must be made between independent dealers and those of the original manufacturers. Independent classic car dealers sell vehicles of various brands. However, in recent years, manufacturers are increasingly utilizing the potential of their own historic vehicles. For example, Mercedes-Benz maintains its own classic car dealership, which is affiliated with the Mercedes-Benz Museum (Mercedes-Benz Museum $\mathrm{GmbH}, 2016$ ). Furthermore, BMW offers access to its Classic Parts Shop over the Internet, through which almost all replacement parts can be ordered for historic BMW vehicles. Moreover, purchase requests for classic BMW cars can be made there (BMW AG, 2016). Finally, the Porsche Classic Shop has a similar offer regarding spare parts and also offers factory restorations (Dr. Ing. h.c. Porsche AG, 2016). The described activities of car dealers show, how profitable the classic car business really is.

\section{Investing in Classic Cars}

Investing in classic Cars comes with special characteristics of this investment class, that have to be taken into account. Historic vehicles are almost unique and hard to replace. Also, the pricing is, apart from auctions for high-priced vehicles, mostly non-transparent (Firlus, 2011). Comparative values can sometimes not be determined consistently as the market for a number of vehicles is subject to intrinsic illiquidity (Lipinski, 2014). In the following, investment forms in the classic car market are described under the outlined conditions as well as with regard to the potential chances and risks.

Generally, direct investments in classic cars and the derivative investments via funds or certificates can be differentiated. As with almost all investment decisions, the factors risk, return and liquidity should be weighted according to the investors' preferences (Benicke, 2006). In the following, it is shown that due to the specificity of the asset class classic cars, there are differences in the two investment forms mentioned beforehand. As it will be shown, seeking the advice of experts and establishing a Classic Car Banking in an existing wealth management structure can be gainful for both, customers and consultants.

The direct investment in classic cars offers not only the chance of a quantifiable return, for example a sales revenue. Considerably more, the investor has the opportunity to realize an emotional return. Only very few asset classes have this feature. Literature suggests, in addition to classic car investments the investment in art in this context (González / Weis, 2000). However, the direct investment in classic cars does not only address a visual-aesthetic level of perception. In the use of the historic vehicle, enjoyment can be perceived in all senses. If the investor has a corresponding affinity, the individual emotional return can therefore play a central role in the investment decision (Merten, 2009).

In addition to the factors emotional return and the influenceability of value described before, tax benefits can arise from the direct investment in classic cars, depending on the individual legal position. In Germany for example, in addition to the reduced motor vehicle tax, the possibility of tax-free profits from private sale transactions after a one-year holding period has to be considered. The direct investment can subsequently lead to a tax optimization for the overall portfolio of private investors ( $\$ 23$ (1) S. 1 Nr. 2 S. 1 read in conjunction with S. 3 Einkommensteuergesetz - EStG) 
Due to the already outlined growing attractiveness of the asset class classic cars and the current market environment, several providers have tried to come up with derivative investments in this asset class, such as funds and certificates. The basic idea lies in the diversification in a portfolio of multiple classic cars, in which the investor participates from profits of resale. However, not all providers could survive on the market. One example is the Classic Cars $\mathrm{GmbH} \&$ Co. KG Fonds Nr. $1 \mathrm{KG}$, which predicted a payout of $210 \%$ after eleven and a half years but had to conclude operations after about three years (Classic Dream Lease GmbH \& Co. Verwaltungs KG, 2010 \& Justizministerium NRW, 2014).

A still active provider in the market of indirect investments in the field of classic cars is the Custoza Family Office. This Zurich-based company offers two forms of participation under the umbrella of The Classic Car Fund for participation in the vintage car market. The two variants differ mainly in the minimum investment. In the product version Class $\mathrm{P}$, an investment is already possible from 10,000 Euros upwards, whereas in Class I only from 200,000 Euros upwards. According to the Family Office, individual vehicles were sold with more than $25 \%$ profit after just more than a few months period (Custoza Family Office Ltd., 2016). Noteworthy about this fund is the legal construction. The Classic Car Fund has been formed by The Classic Car Fund Limited, an investment company registered on the island state of Saint Vincent and the Grenadines (The Classic Car Fund Ltd., 2012).

When examining opportunities and risks of the classic car class asset class, it is expedient to take the already discussed intentions of the acquirers of classic cars into account. For example, investors who are more focused on emotional returns or on enjoyment (A) are less likely to highly appreciate a selling price that is rising as fast as possible than mainly yieldoriented investors (B). Thus, for example, a low selling price (market price risk) for $(B)$ would be perceived as a much greater risk than for (A). In a certain sense, the investor's intentions determine the risk assessment as well as the expected returns on a case-by-case basis.

The potential monetary return of a classic car greatly depends on the individual vehicle. However, on an aggregated level, classic cars indices are available. One example is the DOX - Deutscher Oldtimer Index, which was developed by the German Association of the Automotive Industry in 1999. The DOX tracks and aggregates the performance of 88 vehicles, just as the Dow Jones tracks the performance of the 30 largest corporations in the US. The DOX index was set at 1000 points in the year of its implementation.

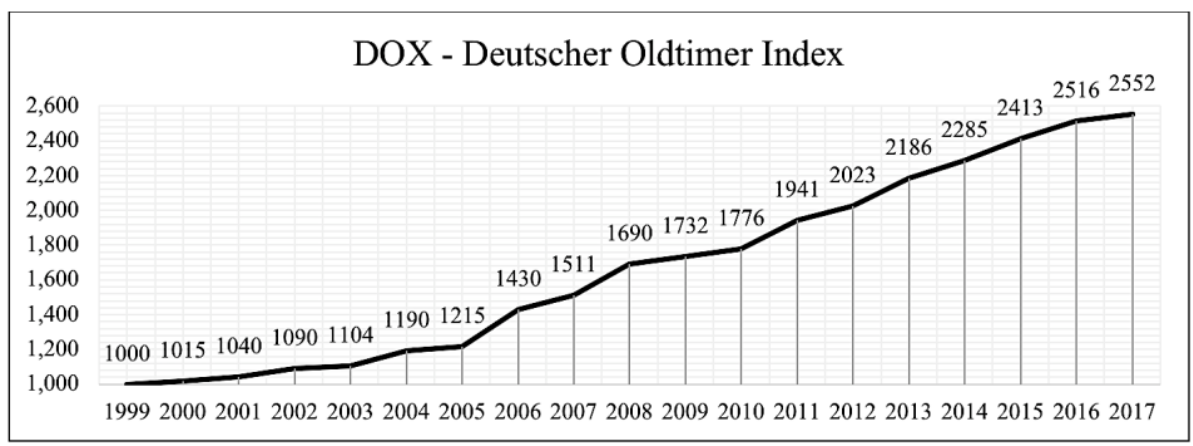

Figure 1 Deutscher Oldtimerindex (DOX) - logarithmic. Figure by author, data from (Verband der Automobilindustrie e.V., 2016).

The optical analysis of the DOX shows a permanently positive development, a feature which cannot be observed in almost any other index. The economic and financial crisis did not dampen the development either. Rather, it turns out that the curve becomes steeper from 2005 on and continues to increase even more.

In addition to the isolated consideration of the classic car as an investment object, the question of portfolio optimization arises in connection with the expected return of the asset class classic cars. In an analysis by Daxhammer and Klein, the correlation between the DOX and the DAX (Deutscher Aktienindex) reveled almost no correlation between the both indices $(r=-0.02)$. In the study, this result was included in the further calculation to develop an optimal portfolio. One of the key findings is, that classic cars are overall able to reduce the risk of a given portfolio (Daxhammer \& Klein, 2016). 
However, the assessment and interpretation of the DOX should be viewed critically. Firstly, the underlying vehicle prices are average values. Nonetheless, individual price deviations are possible in significant magnitudes. Secondly, only observable transactions are included in the evaluation, but many purchases are made privately. A third point of criticism lies in the fact that ongoing costs of classic car owners such as wearing parts, repairs and storage are not taken into account (Brückner, 2010). Even though these costs might consume a significant portion of the return. Finally, the already described emotional return is almost unquantifiable and therefore does not enter the performance of the DOX. Consequently, it can be assumed that there may be significant deviations in terms of return as well as the risk minimizing effect of the classic car investment depending on each individual case.

As already described, the classic car asset class has a number of special features compared to conventional asset classes. In the following, the three specific risks: maintenance costs, market (in)transparency and liquidity will be examined more closely.

The running costs for the preservation of the vehicle consist of various components. In addition to predictable expenses for taxes, insurance or storage, which are necessary to keep the vehicle in working order and thus stable in value, unpredictable costs are a crucial risk. This includes expenses for spare and wear parts as well as expenditures for damages caused by accidents. Due to the age of the vehicles, the search for adequate spare parts is a challenge that in itself binds time and financial resources. The relationship between yield opportunity and maintenance costs is cited in the literature as a central area of tension for this asset class. Since the maintenance costs for higher-priced vehicles are lower in percentage terms, it is noted that, especially in low-cost vehicle categories up to 25,000 Euros, the potential return is usually already eroded by the maintenance costs (Daxhammer \& Klein, 2015). Real chances of a positive net yield are mainly attributed to vehicles from 100,000 Euros upwards (Bender \& Schmidt, 2010).

The market transparency of the classic car market is limited and can lead to a vehicle being acquired at a significantly higher price than a short or medium-term resale would cash out. Moreover, due to the increased activity of speculators on the classic car market, critical deviations for sustainable price formations are observable (Bilanz Deutschland Wirtschaftsmagazin, 2014).

In contrast to the limited ability to already achieve a return with a historic vehicle during the holding period, ultimately only a sale offers the opportunity to realize profit. However, since the investments described are necessary during the holding period to ensure value preservation, this may result in a liquidity risk for the investor. This is worsened if the corresponding market is also characterized by illiquidity and therefore no short sales are possible (Brückner, 2010).

\section{Classic Car Banking in Wealth Management Environments}

There are already first providers of wealth management services in the field of classic cars. However, the topic tends to be considered isolated and focuses primarily on the provision of services to a corresponding customer request for an aboveaverage return (UniCredit Bank AG, 2016). However, when investing in a historic vehicle, in addition to an ex ante hard-toestimate monetary return, the focus is on the emotional return. This circumstance opens up opportunities for wealth management, which is strongly influenced by personal interactions with the customer. Therefore, the approach outlined in the following builds up on the core competence of wealth management: an intensive and holistic relationship management.

The investment strategy for clients in wealth management shows a high degree of individuality. As part of a holistic consultation, tailor-made solutions are developed for the customer (Rizk-Antonious, 2002). In this context, the question of optimizing the portfolio by adding the exotic asset class classic cars may arise. Given certain parameters such as risk appetite, disposable cash, etc., the investment on the market for classic cars can take place. Like any decision in an investment strategy, the investment in classic cars should be regularly reviewed to ultimately ensure customer satisfaction as a critical factor of success in the advisory relationship between customer and wealth management consultant.
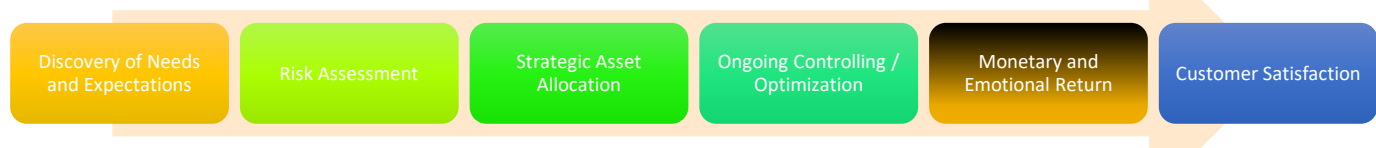
Figure 2 Process of consulting in wealth management with emotional return. Figure by author.

The integration of classic car banking in an existing wealth management structure can be described as a three-step approach. The first level is the core competency of wealth management. This core is formed by classic car-related banking services as well as non-bank classic car related services that can be operated as a brokerage business. The core competence of wealth management focuses on the constant portfolio optimization for clients through an intensive relationship management (Häger \& Raffelsberger, 2005). Moreover, high-quality and exclusive events for customers round off the core competences of wealth management.

Around the described core competencies of wealth management, a comprehensive solution package for the classic car investment should be offered as classic car related banking services. These include offers for financing or leasing historic vehicles. The latter might be worthwhile for tax purposes in certain circumstances (Trockner, 2011). Moreover, an adequate insurance of the vehicle can be provided as a banking / insurance service by consulting experts. The value of the historic vehicle usually increases while the value of a new vehicle decreases. In order to reflect these increases in value and avioid underinsurance, regular valuations are required, which can be forwarded to an insurance company. In this area, there seems to be an even greater need for advice, as insurance coverage of historic vehicles often does not correspond with the value or condition of the vehicle adequately (bbg Betriebsberatungs $\mathrm{GmbH}, 2015$ ).

As already mentioned above, investing in classic cars comes with additional questions that go far beyond traditional investments. Since competences for technical issues cannot be provided in wealth management or a bank generally, it makes sense to set up a network of experts. The wealth management consultants as the central and single point of contact can fall back on those experts if customers require a special service for their classic cars. The network should cover as many possible issues that could arise in the investment process. This ranges from technically-competent purchase advice to professional storage and transport through recommendations for specialist workshops and support at auctions (Kammerer, 2016). This support by experts is essential for the technical layman to create the conditions for a profitable investment.

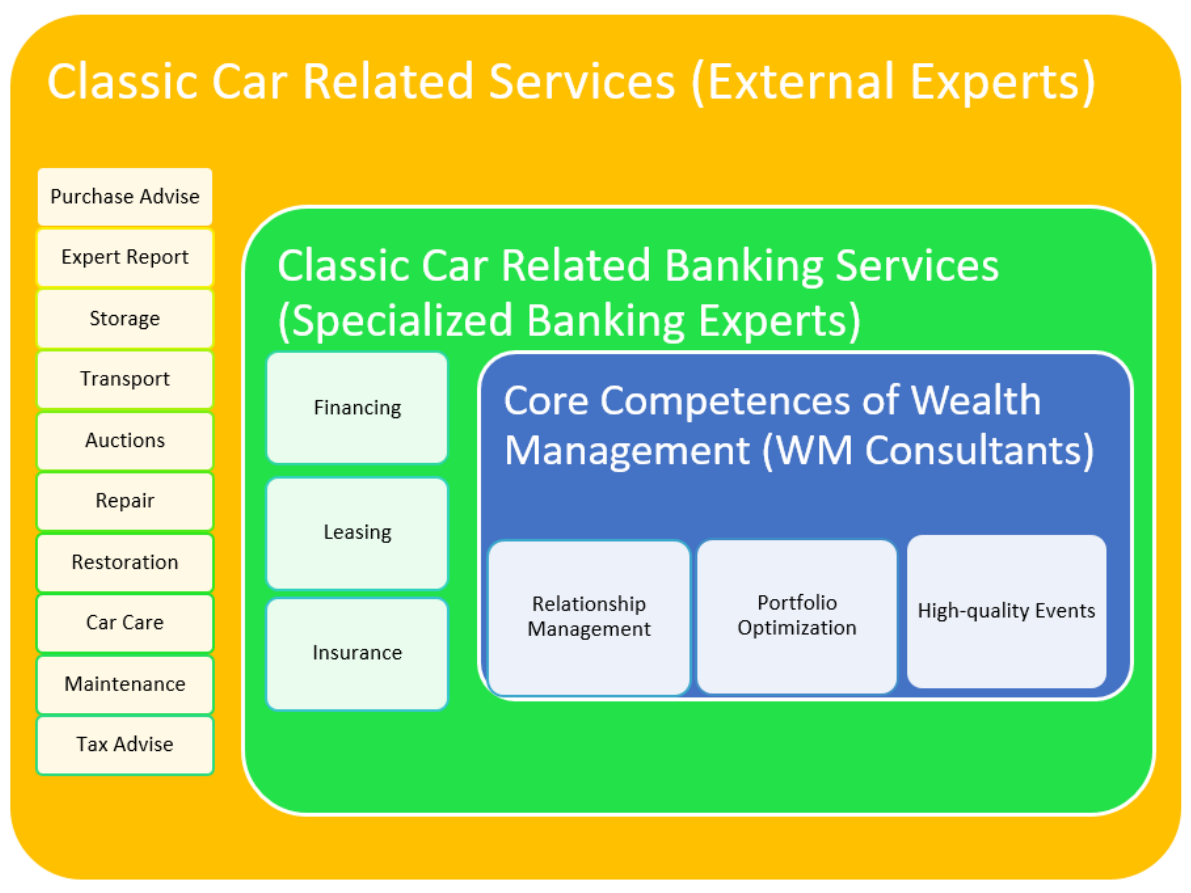

Figure 3 Classic Car Banking in an existing wealth management environment. Figure by author. 


\section{Behavioral Finance and Classic Cars}

Behavioral finance as a subcategory of behavioral economics has been a field of distinct research over the last decades. Contrary to the neoclassic concept of Homo Oeconomicus, behavioral finance suggests, that human rationality is contradicted by cognitive biases and heuristics and therefore susceptible for irrational and inconsistent decisions (Tversky \& Kahneman, 1979). As this paper already proposed, the individual emotional return plays a central role in the investment decision for classic cars. Therefore, this investment decisions are even more prone to inefficiency than other financial decisions without such an emotional component. In the following, four different concepts of behavioral finance will be presented and applied to classic car investments.

Firstly, anchoring as a concept of behavioral finance refers to the observation, that individuals exposed to any kind of information, whether it is related to the matter of decision making or not, are influenced in their decisions, simply because the exposure leads to insufficient adjustments (Tversky \& Kahneman, 1974). By taking the given non-transparency of the classic car market into account, it is likely, that individuals who are about to purchase a vehicle are highly influenced by the sellers offers during negotiations, just because the market does not provide a price assessment for every car in every condition. Subsequently, higher and even out of the market prices might occur, which again makes it harder for investors to benefit financially from the investment.

Secondly, the endowment effect describes the tendency of people to ascribe value to an object mainly because they own it and not because of its special features or actual worth (Kahneman et. al. 1990). In terms of classic cars, this could be especially unfavorable when it comes to reselling the classic car. This particular bias corresponds with the classic car market attribution to be illiquid. Sellers might have a hard time to actually sell their vehicles for a (perceived) convenient price after all the time they owned it and spend additional money for maintenance and other additional costs.

Thirdly, people have a variety of mental accounts that they use to organize, evaluate and keep track of financial issues. The human tendency is, to apply different rules on different mental accounts, whereas costs in the same account are considered less upsetting (Thaler, 1985). Subsequently, this concept of behavioral finance might also explain why people attribute to much value to their classic car and ignore the fact that besides all those follow-up investments, that were necessary to obtain the value of the vehicle, also some follow-up investments clearly have to be considered as sunk costs. The latter most likely won't be recouped in case of a resale. Another aspect of mental accounting in terms of an asset allocation is, that probably the emotional involvement in the classic car leads to insufficient adjustments as far as other asset classes in a given portfolio are concerned. However, this hypothesis needs to undergo further research.

Finally, overconfidence has the potential to withhold financial gain from the classic car investor. Overconfidence actually consist of the three subcategories overprecision, overplacement and overestimation (Moore \& Healy, 2008). In terms of classic car investments, overplacement seems to be one of the most obvious biases that might explain the negative interference of the emotional commitment of an investor with the ambition to realize profit. One example would be an investor, who does not follow the consultants advise to sell the vehicle at a certain point in time, because the investor thinks he knows better when the right time has come. Moreover, a situation in conceivable in which the investor is sure that there is the possibility of an outstanding good purchase ahead, whereas such an assessment can't be made properly due to the non-transparent market and the market illiquidity. If the investor still buys the car, the price payed might be way out of the market.

\section{Conclusion and Outlook}

An end to the low-interest rate situation in Europe and beyond is currently only partially in sight and even in the case of slightly rising interest rates, the question of alternative investment options will continue. Against this background, investing in classic cars represents an alternative investment opportunity for wealth management clients. However, the investor and the consultant should be aware that this can be a highly emotional investment. The latter can give the investor a lot of pleasure and, at a later stage, a sales profit after deduction of all costs. The consultant in contrast has the opportunity to advise clients on a completely new topic and with it, in a different emotional intensity.

However, the investment is not recommended for individuals who have limited loss readiness or who rely on liquidity from a sale in the short and medium term. Ultimately, in the worst case, the emotional return realized over a period of time may be the only return left to the investor. In order to be able to successfully accompany an investment in classic cars, expert 
knowledge is required which the wealth management consultant usually cannot provide in full. Therefore, the involvement of more qualified professionals and experts is required.

Furthermore, due to the possibly highly emotional matter of classic cars, the investor is prone to make common investment mistakes that are known in behavioral finance research. In order to avoid these mistakes, the wealth management consultant should be aware of them and provide objective consulting, even if this might be hard sometimes. The latter can apply to both, the investor and the consultant. The investor might be too attached to the emotional return of the classic car, whereas the consultant might fear to argue controversial with a valued customer.

\section{References}

[1] Anastassiou, C. (2013): Das Gold aus der Garage versichert II. Retrieved June 15, 2018 from http://www.portfolio-international.de/ newsdetails/article/ das-gold-aus-der-garage-versichert-ii.html

[2] bbg Betriebsberatungs $\mathrm{GmbH}$ (Ed.) (2012): Viele Autofahrer bevorzugen Oldtimer als Wertanlage. AssCompact. Das Fachmagazin für Risiko- und Kapitalmanagement, 14 (3): 53.

[3] bbg Betriebsberatungs $\mathrm{GmbH}$ (Ed.) (2015): Oldtimer: Haftungsübernehme für Makler. AssCompact. Das Fachmagazin für Risiko- und Kapitalmanagement, 17 (12): 40-41.

[4] Barzilay, D. (2009): Collecting Classic Cars. In: Satchell, S. (Ed.), Collectible investments for the high net worth investor. (pp. 245-255), Oxford.

[5] Bender, J. \& Schmidt, H. (2013): Renditejagd im Zinstief. Retrieved May 25, 2018 from http://www.ntv.de/ratgeber/Diese-Geldanlagen-gibts-nicht-bei-der-Bank-article10960146.html

[6] Benicke, C. (2006): Wertpapiervermögensverwaltung. In: Max-Planck-Institut für ausländisches und internationales Privatrecht (Ed.), Beiträge zum ausländischen und internationalen Privatrecht, Bonn.

[7] Bilanz Deutschland Wirtschaftsmagazin (Ed.) (2014): Nur etwas für Millionäre? BILANZ, 1 (6): 71.

[8] BMW AG (Ed.) (2016): BMW Classic Teile Shop. Retrieved May 15, 2018 from http://shop.bmw-classic.de/isbin/INTERSHOP.enfinity/WFS/Classic-ClassicDE-Site/de_DE/-/EUR/ViewApplication-DisplayWelcomePage

[9] Brückner, M. (2013): 50 Sachwerte die Sie ruhig schlafen lassen. München.

[10] Brückner, M. (2010): Stilvoll investieren. Geldanlage mit emotionaler Rendite. Berlin.

[11] Classic Dream Lease GmbH \& Co. Verwaltungs KG (Ed.) (2010): Classic Cars GmbH \& Co. Fonds Nr. 1 KG. Grünwald.

[12] Daxhammer, R. \& Klein, K. (2015): Oldtimer als Wertanlage - Die Eignung des Oldtimers als Investment- und Diversifikationsobjekt. In: Beyer, H.-M. \& Daxhammer, R. (Ed.), Reutlinger Diskussionsbeiträge zu Finanz \& Rechnungswesen 2015-1. Reutlingen.

[13] Dr. Ing. h.c. F. Porsche AG (Ed.) (2016): Porsche Classic Online Shop. Retrieved May 15, 2018 from http://www.classicshop.porsche.com/ pcos/zentralseite

[14] Custoza Family Office Ltd. (Ed.) (2016): About us. Retrieved May 21, 2016 from

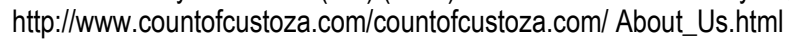

[15] Euler, C. (2014): Alternative Geldanlage. Investieren mit Leidenschaft. SteuerConsultant, 8 (2): 30-33.

[16] Firlus, T. (2011): Bewegtes Investment. Wirtschafts Woche, 2011 (38): 108.

[17] González, T. \& Weis, R. (2000): Kunst-Investment. Die Kunst mit Kunst Geld zu verdienen. Wiesbaden.

[18] GTÜ Gesellschaft für technische Überwachung mbH (Ed.) (2016): 17 Fragen und Antworten zu Oldtimern und der Oldtimer-Richtlinie. Stuttgart.

[19] Häger, J. \& Raffelsberger, A. (2005): Private Banking. Kundenbindung und Ertragssteigerung in der Praxis. Wiesbaden.

[20] Jahnstone, I. (2014): Price watch Bentley R-type. Classic \& Sorts Car, 32 (7): 213.

[21] Justizministerium NRW (Ed.) (2014): Veröffentlichungen. Retrieved May 25, 2016 from https://www.handelsregister.de/rp_web/directdownload.do;jsessionid=86BAB70CBBFC9D21AEFA1A26EF68087 F.tc05n01?id=3

[22] Kahneman, D. \& Knetsch, J. L. \& Thaler, R. H. (1990): Experimental Tests of the Endowment Effect and the Coase Theorem.Journal of Political Economy, 98 (6): 1325-1348.

[23] Kammerer, L. (2016): Mit Leidenschaft und kühlem Kopf. Auto Service Praxis, 20 (2): 16-17.

[24] Kräussl, R. (2015a): Der Steve-McQueen-Effekt. Manager Magazin, 45 (1): 110.

[25] Kräussl, R. (2015): Rendite aus Leidenschaft. Manager Magazin, 45 (2): 95. 
[26] Lipinski, G. (2014): Rollende Raritäten. Sparkasse Managermagazin 27.10.2014. Retrieved June 15, 2016 from https://www.sparkassenzeitung.de/rollende-raritaeten/150/153/48388/

[27] Mercedes-Benz Museum GmbH (Ed.) (2016): All Time Stars. Ihr Traum von einem klassischen MercedesBenz. Retrieved June 15, 2018 from http://alltime-stars.com/fahrzeuge/

[28] Merten, H-L. (2009): In Luxus investieren. Wiesbaden.

[29] Merten, H.-L. (2015): Kunst und Luxus als Kapitalanlage. Vermögenssicherung und Rendite mit exklusiven Sachwerten. Regensburg.

[30] Moore, Don A. \& Healy, Paul J. (2008). "The trouble with overconfidence". Psychological Review, 115 (2): 502-517.

[31] Rotz, B. (2012): Sind klassische Autos von berühmten Vorbesitzern mehr wert?. Retrieved May 16, 2018 from http://www.zwischengas.com/ de/blog/2012/02/13/Sind-klassische-Autos-von-beruehmten-Vorbesitzern-mehrwert-.html

[32] Ritk-Antonious, R. (2002): Qualitätswahrnehmung aus Kundensicht. Wiesbaden.

[33] Sauren, E. (2015): Die Zinsfalle. Die neue Bedrohung für konservative Anleger - Gefahren für das Portfolio erkennen und vermeiden. München.

[34] Thaler, Richard H. (1985). Mental Accounting and Consumer Choice. Marketing Science, 4 (3): 199-214.

[35] Thaddeus, M. (2012): How to restore Classic Car Bodywork. Dorchester.

[36] The Classic Car Fund Limited (Ed.) (2012): The Classic Car Fund. Kingstown.

[37] Trockner, M. (2011): Steigen Sie ein! Oldtimer. Capital, 50 (4): 153-159.

[38] TÜV Süd Autoservice GmbH (Ed.) (2012): Anforderungskatalog für die Begutachtung von Oldtimern. München.

[39] Tversky, A. \& Kahneman, D. (1974): Judgment under Uncertainty: Heuristics and Biases. Science, 185 (4157): 1124-1131.

[40] Tversky, A. \& Kahneman, D. (1979): Prospect Theory: An Analysis of Decision under Risk. Econometrica, 47 (2): 263-292.

[41] UniCredit Bank AG (Ed.) (2016): Classic Cars - in emotionale Rendite investieren. Retrieved June 15, 2018 from https://www.hypovereinsbank.de/portal?view=/de/private-banking/vermoegen/classic-cars.jsp

[42] Verband der Automobilindustrie e.V. (Ed.) (2018): Indexentwicklung seit 2008. Retrieved June 17, 2018 from https://www.vda.de/dam/vda/Medien/DE/Presse/Oldtimer-Index_Infografiken-vom-Maerz2018/VDA_04184_Oldtimer_Indexentwicklung_DE_prin 